\title{
Social media use and impact during the holiday travel planning process
}

\author{
John Fotis ${ }^{\mathrm{a}}$, Dimitrios Buhalis ${ }^{\mathrm{a}}$ and Nicos Rossides ${ }^{\mathrm{b}}$ \\ ${ }^{\mathrm{a}} \mathrm{School}$ of Tourism, \\ Bournemouth University, U.K. \\ \{jfotis, dbuhalis\}@bournemouth.ac.uk \\ ${ }^{\mathrm{b}}$ MASMI Research Group, \\ Cyprus \\ nicos.rossides@masmi.com
}

\begin{abstract}
Through an empirical study among holiday travellers, residing in the Former Soviet Union Republics, this paper presents a comprehensive view of role and impact of social media on the whole holiday travel planning process: Before, during and after the trip, providing insights on usage levels, scope of use, level of influence and trust. Findings suggest that social media are predominantly used after holidays for experience sharing. It is also shown that there is a strong correlation between perceived level of influence from social media and changes made in holiday plans prior to final decisions. Moreover, it is revealed that user-generated content is perceived as more trustworthy when compared to official tourism websites, travel agents and mass media advertising.
\end{abstract}

Keywords: Social media; travel planning process; holidays

\section{Introduction}

As early as in 2006 it was argued that social media started replacing traditional sources of information (Jepsen, 2006). Later, it has been supported that social media might influence the buying behaviour process; at least as described in InputsProcessing-Response models (Constantinides \& Fountain, 2008). Moreover, De Valck, Van Bruggen, \& Wierenga (2009) suggested that virtual communities are becoming important networks of consumer knowledge that influence consumer behaviour. Today, social media enjoy a phenomenal rise in their popularity among internet users: Facebook claims that its active users reached more than 750 million worldwide, spending more than 700 billion minutes per month (Facebook, 2011); Twitter hosts 175 million users who on an average week post one billion tweets (Twitter, 2011); YouTube users view daily over 3 billion videos (YouTube, 2011); and it is estimated that there are over 170 million blogs worldwide (BlogPulse, 2011).

In tourism, consumers' behaviour has always been influenced by developments in Information Communication Technologies (Buhalis, 1998; Poon, 1993), and especially it is Web 2.0 that dramatically changed how consumers plan and consume travel related products (Buhalis \& Law, 2008). Gretzel, Kang, \& Lee (2008) predicted that social media impacts in travel will be tremendous. In 2008 it was found that $82 \%$ of US online consumers have checked online reviews, blogs and other online feedback for their travel related purchasing decisions (eMarketer, 2008). Today, TripAdvisor, perhaps the leader among travel related consumer review websites (a subset type of social media), serves more than 50 million users per month who seek 
advice about their travel plans and hosts more than 50 million travel reviews and opinions (TripAdvisor, 2011). Moreover, it is argued that social media "are taking an important role in travellers' information search and decision-making behaviours" (Yoo, Gretzel, \& Zach 2011, p. 526).

To further describe the impact of social media in holiday travel, this study attempts to measure social media usage levels and scope during the whole travel planning process (pre, during and post-trip). Furthermore it attempts to measure perceived level of social media influence on destination and accommodation choice, as well as perceived level of trust to social media content in relation to other sources of travel related information.

\section{Literature Review}

\subsection{Social media}

Kaplan and Haenlein (2010, p.61) define social media as "a group of Internet-based applications that build on the ideological and technological foundations of Web 2.0, and that allow the creation and exchange of User Generated Content". Although there are a number of approaches in terms of social media taxonomies (Constantinides, 2009; Fischer \& Reuber, 2011; Kim, Jeong, \& Lee, 2010; Mangold \& Faulds, 2009) Kaplan and Haenlein (2010) proposed a taxonomy scheme that classifies social media types according to their (a) level of social presence / media richness, and (b) level of self presentation / self disclosure, identifying six types of social media: social networking websites (i.e. Facebook, Linkedin), blogs, content communities (i.e.YouTube, Flickr, Scrib, Slideshare, Delicious), collaborative projects (i.e. Wikipedia, Wikitravel), virtual social worlds (i.e. Second Life), and virtual game worlds (i.e. World of Warcraft). Still however, such a taxonomy neglects other types of social media such as microblogs (i.e. Twitter), consumer review \& rating websites (i.e. TripAdvisor, Epinions) and internet fora (i.e. ThornTree, Fodor's Travel Talk).

\subsection{Social media in Travel}

Holiday travel related purchases are considered complex due to the composite and experiential nature of the holiday travel product, involve high risks and as a result require extensive information search (Sirakaya \& Woodside, 2005). Within such information search processes, consumers rely on other travellers' experiences as a mean to increase the exchange utility and decrease uncertainty (Kotler, Bowen, \& Maken, 2010; Litvin, Goldsmith, \& Pan, 2008; Yoo, Lee, \& Gretzel, 2007). Just after the creation of the first virtual communities (Rheingold, 1993) it became apparent that their online content was perceived similar to recommendations provided by friends, family and "like-minded souls" (Fernback \& Thompson, 1995; Wang, Yu, \& Fesenmaier, 2002). During the Web 2.0 era social media applications "exploded" in popularity, usage levels providing a plethora of characteristics enabling self expression and sharing of content. Ad-ology supports that $23 \%$ of US Internet users were "somewhat" or "significantly influenced" by social media for their travel / holiday related decisions (eMarketer, 2010). Social media are therefore becoming increasingly important in travel planning, primarily for their function as vital 
information sources providing access to other travellers' experiences (Chung \& Buhalis, 2008; Yoo et al., 2011). At the same time, apart from their function as information sources, social media enable storytelling, a usual post-travel activity, on a ' $24 / 7$ ' basis to large audiences, and also provide a sense of belonging into virtual travel communities (Gretzel, Fesenmaier, \& O'Leary, 2006).

A number of studies focus on the impact and role of social media in travel related decisions: Gretzel, Yoo, \& Purifoy (2007) found that online reviews posted in a travel related consumer review and rating website increase travellers' confidence during decision making, reduce risk, assist them in selecting accommodation and therefore facilitate decision making. Moreover, it was found that travellers read accommodation reviews throughout the various stages of the travel planning process: Before travel as a source of ideas, as a mean to narrow down choices, and post accommodation choice in order to confirm the choice made; during the trip; after the trip to compare and share experiences; but also as an ongoing process even if there is no trip ahead. Mack, Blose, \& Pan (2008) studied the influence and credibility of travel blogs and found that traditional WOM is more trustworthy than blog posts, suggesting that WOM generated from sources with which travellers have strong social ties is more trustworthy than WOM from strangers. However, they found that those who post in blogs perceive the authoritativeness of blogs as similar to that of traditional WOM, leaving space for future improvement of blogs' credibility as the number of those who post to blogs increases over time (Technorati, 2010). Yoo, Lee, Gretzel, \& Fesenmaier (2009) found that user generated content is perceived as more credible when posted to official tourism bureau sites rather than in review sites, travel blogs social networking sites and content communities. Vermeulen \& Seegers (2009) studied consumer reviews' impacts on choice of accommodation and found that the consideration of a hotel is enhanced by exposure to both negative and positive consumer reviews. In their attempt to reveal the role of social media throughout the travel planning process, Cox, Burgess, Sellitto, \& Buultjens (2009) found that social media are mostly used before the trip, while during and after the trip their use was very limited. More specifically, social media were primarily used after the holiday destination choice rather than during the evaluation of destination choices. Moreover, social media were perceived as less trustworthy than traditional sources of information (i.e. official tourism websites and travel agents). It may be argued however, that such a result may be attributed to the fact that the study's sample was derived from a mailing list of an official tourism website and therefore there may be a positive predisposition towards official sources of information. White (2010) suggests that travel related photos in Facebook generate interest to viewers and can very easily become part of the viewer's travel plans. Contrary to findings of Mack et al. (2008), and Yoo et al. (2009), Del Chiappa (2011) supports that trustworthiness of tourismrelated blogs is second only to consumers' reviews and ratings found in online travel agents' websites.

In parallel with the argument made by Parra-López, Bulchand-Gidumal, GutiérrezTaño, \& Díaz-Armas (2011), the above discussion also suggests that the majority of existing studies attempt to describe the role of social media either focusing on specific types of social media and specific communities, or at a specific stage of the travel planning process, evidencing that there is no adequate academic research on the role 
and impact of social media as a whole throughout the holiday travel planning process. This study presents an attempt to address this gap and pursues the following research questions and resulting hypotheses:

RQ1: To what extent and for what reasons are social media used during the holiday travel planning process?

H1: Social media are predominantly used before the trip for information search purposes.

RQ2: Do social media influence holiday plans?

H2: The higher the perceived level of social media influence on holiday destination choice or accommodation choice, the more likely is that changes would be made to holiday plans.

RQ3: Are social media more trustworthy than traditional sources of holiday related information?

H3: Holiday travel related information provided in social media is more trustworthy than mass media advertising, travel agents and official tourism websites.

\section{Methodology}

\subsection{Data Collection}

An online questionnaire survey was conducted in October 2010 in a random subset of a commercial online research panel whose members are residing in 12 Former Soviet Union Republics (F.S.U.) including Russia. An e-mail invitation was sent to 900 panellists containing a link to the online questionnaire. Without any reminder 368 panel members completed the questionnaire achieving a response rate of $41 \%$. Respondents had the option to complete part of the questionnaire, and as a result 22 questionnaires were incomplete, thus 346 questionnaires were used for further analysis. Through a screening question it was assured that all respondents have taken at least one holiday trip during the last 12 months. As a result the sample of the study consists of 346 internet users residing in 12 F.S.U. Republics who have taken at least one holiday trip within 12 months prior to the study. The questionnaire included an introductory statement explaining types of websites considered as social media within six broad categories: Blogs, photo \& video sharing websites, microblogs, wikis, social networking websites and travel review websites. This taxonomy was created by the authors after a review of existing literature (Constantinides, 2009; Fischer \& Reuber, 2011; Kim, Jeong, \& Lee, 2010; Mangold \& Faulds, 2009; Xiang \& Gretzel 2010). For each of the above types a number of examples were given in order to increase the reliability of the instrument. Examples included websites not only among those dominating the western world but also websites operating exclusively within F.S.U. Republics such as Vkontakte.ru and Odnoklassniki.ru in terms of social networking websites.

\subsection{Measures}

The questionnaire was exclusively designed for the purposes of this study. Respondents were asked to recall their last holiday trip within the last 12 months, the 
destination country of this trip and the nights spent there. Three sets of multiple response questions were used to measure social media use before, during and after the holiday trip. A total of 12 statements providing different reasons for social media use were used, of which five were borrowed from Cox et al. (2009). Perceived level of social media influence on destination and accommodation choice was measured a 7point scale ranging from "Not Influential At All" (1) to "Very Influential" (7) transforming a five point scale used by Lo, Cheung, \& Law (2002) to a seven point scale. Perceived level of trust to holiday travel related information sources was measured by a seven point Likert scale ranging from "Strongly Disagree" (1) to "Strongly Agree" (7) as per Cox et al (2009). Of the seven statements used to describe an equal number of information sources, four were borrowed from Cox et al. (2009) to enable comparison of findings. The questionnaire also included, among other, measures to provide socio-demographic characteristics and travel behaviour.

\section{Results}

\subsection{Profile of Sample}

The sample had the following characteristics: As per the gender, $65.6 \%$ were females and $34.4 \%$ males. The over representation of female respondents has been also observed in other studies (Cox et al., 2009; Gretzel et al., 2007), and may to an extent be related to gender differences in holiday-related roles (Decrop, 2006; Mottiar \& Quinn, 2004). As per the age 18.2\% were less than 25 years, 38.4\% from 25 to 39 , $30.9 \%$ from 40 to 54 , and $12.5 \% 55$ or older. As per the education, $30.3 \%$ have completed secondary school, and $69.7 \%$ were university graduates. Moreover, $64.2 \%$ were residing in Russia, and $35.8 \%$ in the other FSU Republics, a proportion that approximates the distribution of actual internet users between the two regions (InternetWorldStats, 2010).

\subsection{Use of social media}

The vast majority of respondents $(97 \%)$ have visited at least one social media website during the last 12 months. Almost half (49\%) of respondents visited social media websites several times a day, 36\% almost every day, $9 \%$ only sometimes per week, and $3 \%$ very rarely. Level of use was found to be differentiated by age, $\chi^{2}(15, \mathrm{~N}=$ $346)=34.99, p=.01$, and level of education, $\chi^{2}(5, \mathrm{~N}=346)=11.92, p=.04$. The vast majority (94\%) of respondents "below 25 " visit social media websites "several times a day" or "almost every day", whereas among those "55 and over" the same usage level decreases to $72 \%$. In terms of level of education, $88 \%$ of university graduates visit social media websites "several times a day" or "almost every day", whereas among those who completed secondary school the same usage level decreases to $79 \%$.

\subsection{Social media usage levels and reasons for use during the holiday planning process}

Figure 1 reveals that among the three stages of the travel planning process (before, during, and after the trip) it is after the trip that social media are predominantly used for the purpose of sharing experiences and photos with friends and/or other travellers. More specifically before their holiday trip $45 \%$ of respondents searched for ideas on 
where to go for holidays, and $42 \%$ seek ideas and information on excursions and other leisure activities. The analysis did not reveal any significant differences among age groups, level of education, and region of residence. Gender differences were observed only in usage levels for the purpose of confirming that a good destination choice was made, $\chi^{2}(1, \mathrm{~N}=346)=4.64, p=.03$, since $35 \%$ of females used social media for that purpose as opposed to $24 \%$ of men.

During the holiday trip, respondents primarily used social media for a non-holiday related reason: to stay connected with their friends $(50 \%)$, and to a lesser extent to find holiday related information (30\%). Providing comments and reviews about the holiday experience, while at the destination, engaged only $17 \%$ of respondents, however significant differences among age groups were observed, $\chi^{2}(3, \mathrm{~N}=346)$ $=10.62, p=.01$ : One every four holidaymakers "below 25 " posted reviews during trip, a percentage that drops to $9 \%$ for those aged 40 and above.

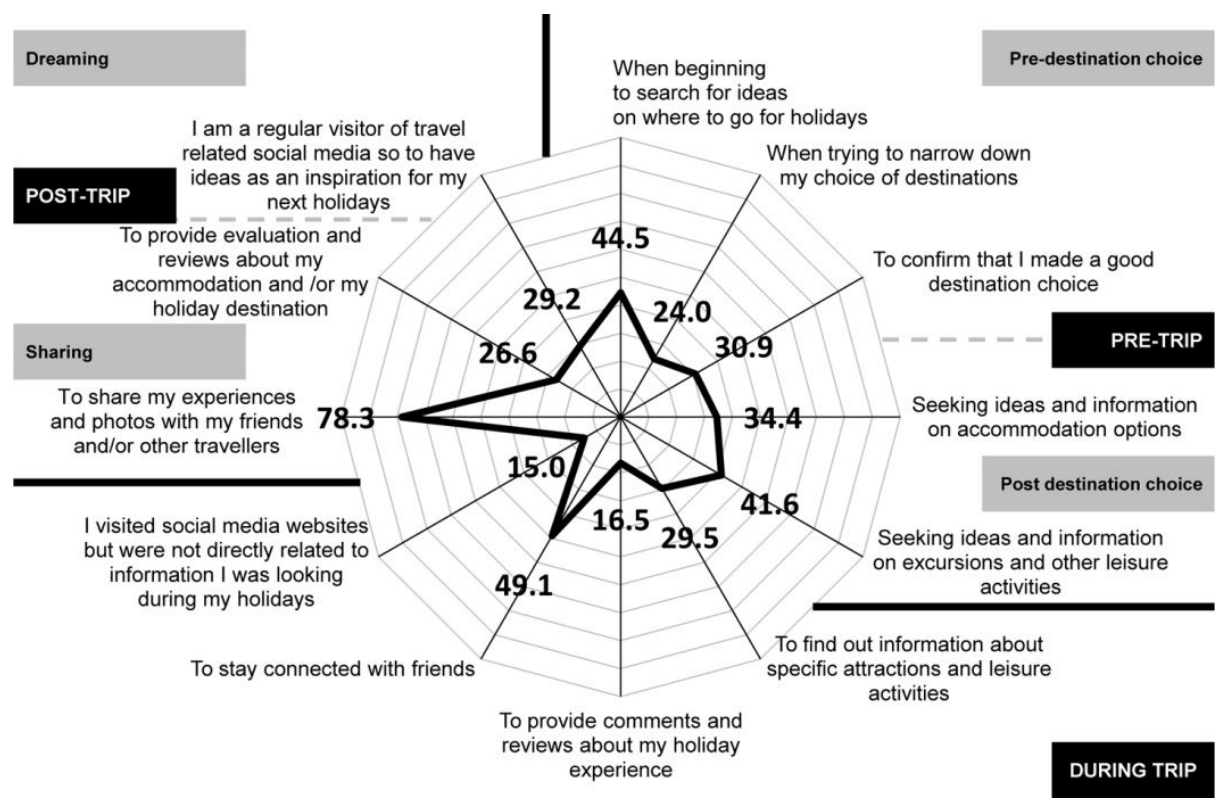

Fig. 1. Percentage (\%) of respondents that used social media during their travel planning process and reasons of use

It is after the holiday trip that respondents primarily used social media, as $78 \%$ used them to share experiences and photos with friends and / or other travellers. Providing reviews and evaluations engaged $27 \%$ of respondents, however such activity level differentiates among age groups, $\chi^{2}(3, \mathrm{~N}=346)=12.28, p=.01$. More than a third $(36 \%)$ of respondents between 25 and 39 engaged in such activity, as opposed to only $12 \%$ of those aged over 55 .

From the above discussion it is evident that H1 (Social media are predominantly used before the trip for information search purposes) is rejected. This finding is in contrast 
with Cox et al. (2009) who found that social media are predominantly used during the before the trip stage for information search purposes.

\subsection{Social media influence on holiday plans}

Perceived level of social media influence on holiday planning was assessed in terms of destination choice, accommodation choice and changes made to holiday plans before the final decision. Social media perceived level of influence on destination choice was measured at $4.84(\mathrm{SD}=1.63)$ and on accommodation choice on 4.61 (SD $=1.81$ ) both on a 1-7 scale. Independent samples t-tests and one-way analysis of variance did not reveal any significant differences in gender, education level, age, frequency of travel, or region of residence.

To assess change in holiday plans, respondents who visited social media websites while they were still planning their holiday trip $(n=273)$ were asked: "Before your final decisions about your last holiday, did you make any changes to your original holiday plans because of other travellers' opinions, reviews, photos, videos, or other information that you found in social media websites?" Table 1 presents the findings.

Table 1. Social media level of influence and changes in original holiday plans

\begin{tabular}{lccc}
\hline & $\begin{array}{c}\% \\
\text { respondents } \\
(\mathrm{n}=273)\end{array}$ & $\begin{array}{c}\text { Influence on } \\
\text { destination choice } \\
\text { Mean scores* }\end{array}$ & $\begin{array}{c}\text { Influence on } \\
\text { accommodation choice }\end{array}$ \\
\hline I am not sure / cannot remember & $2.2 \%$ & $2.75(1.50)$ & $2.75(2.36)$ \\
$\quad$ if I made any changes & $33.7 \%$ & $4.10(1.80)$ & $3.93(1.91)$ \\
$\begin{array}{c}\text { I did not make any changes } \\
\text { I did make few changes }\end{array} \quad$ to my original holiday plans & $49.5 \%$ & $5.25(1.37)$ & $5.02(1.58)$ \\
$\begin{array}{l}\text { I did make significant changes } \\
\text { to my original holiday plans }\end{array}$ & $14.7 \%$ & $5.35(1.21)$ & $5.00(1.73)$ \\
\hline Pearson Correlation test: & & $r(268)=.34, p<.001$ & $r(268)=.27, p<.001$ \\
\hline
\end{tabular}

$(*)$ Measured on a 7-point Likert scale, where: $1=$ Not influential at all, $7=$ Very influential

The Pearson correlation test was employed to test $\mathrm{H} 2$ (The higher the perceived level of social media influence on holiday destination choice or accommodation choice, the more likely is that changes would be made to holiday plans). In both cases (Table 1) $p<.001$ evidencing that (a) as influence from social media on destination choice increases the more likely is that there are changes in the holiday plans, and (b) as influence from social media on accommodation choice increases the more likely is that there are changes in the holiday plans. As a result hypothesis $\mathrm{H} 2$ is accepted.

\subsection{Trust towards social media and traditional sources of information}

Respondents were asked to indicate their agreement or disagreement with seven statements in the form of "I trust information about holidays provided by..." followed by the information source. As it can be seen in Table 2, friends and relatives are the most trustworthy source of information, followed by information provided by other travellers in various websites, whereas advertisements in mass media are the least trustworthy among the information sources examined. 
Table 2: Perceived level of trust in holiday-related information sources

\begin{tabular}{ll}
\hline I trust information about holidays provided by... & Mean (SD) \\
(N=346, 7-point Likert scale:1=Strongly Disagree, 7 = Strongly Agree) & \\
\hline Friends and relatives & $6.36(1.14)$ \\
Information provided by other travellers in various websites & $5.15(1.41)$ \\
Social media & $4.61(1.37)$ \\
Official tourism websites (state / government owned) & $4.36(1.57)$ \\
Shows or documentaries in TV, in radio, or articles in newspapers and & $3.97(1.45)$ \\
magazines & $3.83(1.36)$ \\
Travel agents & $3.56(1.35)$ \\
\hline Advertisements in TV, radio, newspapers and magazines
\end{tabular}

The above findings are in disagreement with of Cox et al. (2009) who using the same scale found that official tourism websites and travel agents are more trustworthy in comparison to "comments made by travellers on third party sites e.g. TripAdvisor". One potential reason to explain the increased level of trust in official tourism websites observed in Cox et al. (2009) may be that their sample was taken from the database of e-mail subscribers of a destination's official tourism website. As a result, it may be argued that the sample had a positive predisposition or even a preference towards official sources of information.

To test H3 (Holiday travel related information provided in social media is more trustworthy than mass media advertising, travel agents and official tourism websites) one-sample t-tests evidence that the value of 5.15 (observed as a mean level of trust of information provided by other travellers in various websites) is significantly different to the means observed for official tourism websites $t(345)=-9.442, p=.000$; travel agents, $t(345)=-18.019, p=.000$; and mass media advertising $t(345)=-21.890, p=$ .000 . As a result, hypothesis $\mathrm{H} 3$ is accepted.

\section{Conclusions, Limitations and Implications}

This paper contributes to the current literature on the use and impact of social media on holiday travel planning. Contrary to the majority of existing studies that are medium or community specific, or focus in a specific stage of the travel planning process, this study attempts to provide a comprehensive picture on the impact of social media as a whole, throughout the travel planning process. In relation to the study of Cox et al. (2009) this study attempts to describe social media use and impact during the last holiday trip, therefore it attempts to depict actual and not hypothetical travel behaviour (Beaulieu \& Schreyer, 1985, cited Um \& Crompton, 1990). Moreover, by focusing at travellers residing at F.S.U. Republics, a market with distant national culture characteristics to those of the Australian culture, it attempts to add to the discussion raised by Gretzel et al. (2008) that there are differences in terms of social media use among national markets.

This study shows that social media are used during all stages of the holiday planning process (before, during and after holidays) however, to a different extent and for a different purpose. In contrast to the findings of Cox et al. (2009) who found that social media are predominantly used during the information search stage of the travel planning process, this study evidences that travellers residing in the F.S.U. Republics 
use social media predominantly during the post-trip stage for sharing experiences and photos with friends and/or other travellers. It may be argued that such a finding is associated primarily with Russian's high level of engagement with social networking websites (comScore, 2010), although residents of the other F.S.U. Republics do not seem to differentiate. The second most popular use of social media was observed during holidays: as means to enable travellers to stay connected with friends. Both the first and the second most popular uses of social media observed in this study may be attributed to the very low individualist / very high collectivist nature of the Russian culture (Hofstede, Hofstede, \& Minkov, 2010).

In terms of perceived level of influence, social media were rated as "somehow influential" on both destination and accommodation choice. However, more than six out of ten $(65 \%)$ respondents stated that they indeed made some sort of changes to their original plans because of exposure to user-generated content in social media websites, with $50 \%$ describing them as "few changes" and $15 \%$ as "significant changes". Moreover, the present study reveals a strong correlation between social media level of influence on destination and accommodation choice, and the changes made in holiday plans before final decisions were taken. More specifically, as the perceived level of influence from social media on destination choice increases, the more likely is that there were changes to holiday plans in terms of destination selection. Similarly, as perceived influence from social media on accommodation choice increases the more likely is that there were changes in the holiday plans in terms of accommodation selection.

This study also examined the perceived level of trust among seven holiday related information sources: Official tourism websites, publicity and advertorials in mass media (i.e. TV or radio shows and documentaries, newspapers and magazines' articles), advertisements in mass media, travel agents, social media, friends and relatives, and information from other travellers in various websites. Among those, friends and relatives were rated as the most trustworthy source, followed by information from other travellers in various websites. In contrast to the findings of Cox et al. (2009) who found that state tourism websites and travel agents outscored, in terms of trustworthiness, comments by other travellers found in third party sites (i.e.TripAdvisor), blogs and social network sites, this study found that information from other travellers in various websites is trusted more than official tourism websites, and travel agents.

Finally, it should be stated that a comparison of the findings of this study to that of Cox et al. (2009), at least for the constructs that are identically operationalized in both studies, contributes to the empirical confirmation of the claim made by Gretzel et al. (2008) that there are differences in terms of social media use among national markets. More than that, such a comparison suggests that among national markets, apart from differences in social media adoption and use, there are also indications for differences in the perceived level of trust towards social media. Such differences may not be present in closely related national cultures (as this study evidences by examining Russians and residents of the other F.S.U. Republics), however, there are indications that differences are more evident when comparing distant national cultures such as Australians (as per the case in Cox et al. 2009) and Russians. Based on Hofstede et al. (2010) Australians and Russians differ significantly in all four cultural dimensions: in 
power distance (Russia: 93, Australia: 36); in individualism (Russia: 39, Australia 90); in uncertainty avoidance (Russia: 95, Australia: 51); and in masculinity (Russia: 36, Australia: 61).

\subsection{Research Limitations}

Three limitations apply for this study: (a) The sample is not random due to the selfresponse nature of the specific online panel survey; (b) there was no treatment for non-responses; and (c) findings apply only to the specific geographical context (F.S.U. Republics) and therefore cannot be generalized especially to other national markets with distant cultural characteristics.

\subsection{Managerial implications}

This study provides insights and guidelines to industry practitioners to enable them fine tune their social media campaigns in the F.S.U. Republics. First, this study provides evidences that social media are being used during all stages of the holiday travel planning process, however to a different extent and for a different scope. Second, in combination with the work of Cox et al. (2009) this study provides preliminary indications that national source tourism markets behave differently not only in terms of social media adoption and usage levels, but also in terms of scope of use, as well as in perceived levels of trust among travel related information sources. Such a finding clearly suggests that national source markets should be studied individually prior to the design and implementation of social media campaigns. Third, the "during the holidays" stage remains a challenging domain, as social media seem to be used primarily for maintaining contact with friends, while providing comments and reviews on the spot is a least preferred activity. Fourth, in terms of the context of this research, there are only minor differences between Russia and the other F.S.U. Republics source markets in terms of the impact of social media on the holiday planning process, therefore, there is no need for major differentiation in social media campaigns aiming at travellers in those two regions.

\subsection{Suggestions for further research}

The findings of this study suggest that social media travel related research should place equal emphasis in all stages of the travel planning process. Moreover, taking into account the findings of Cox et al. (2009) among Australian internet users and the findings of the present study, it can be claimed that the impact of social media on holiday related travel planning differs among tourism source markets, with cultural differences contributing to such a difference. As a result, an adequate number of cross-cultural studies are needed to substantiate such a claim.

\section{References}

BlogPulse. (2011). Blogpulse Stats. Retrieved from www.blogpulse.com.

Buhalis, D. (1998). Strategic use of information technologies in the tourism industry. Tourism Management, 19(5), 409-421.

Buhalis, D., \& Law, R. (2008). Progress in information technology and tourism management: 20 years on and 10 years after the Internet - The state of eTourism research. Tourism Management, 29(4), 609-623. 
Chung, Y., \& Buhalis, D. (2008). Information Needs in Online Social Networks. Information Technology \& Tourism, 10(4), 267-281.

comScore. (2010). Russia has the most engaged social networking audience worldwide. Retrieved from http://www.comscore.com/Press Events/Press Releases/2010/10/ Russia_Has_Most_Engaged_Social_Networking_Audience_Worldwide

Constantinides, E. (2009). Social Media / Web 2.0 as Marketing Parameter: An Introduction. Paper presented at the International Marketing Trends Conference. Retrieved from http://marketing-trends-congress.com/2009_cp/Materiali/Paper/Fr/Constantinides.pdf

Constantinides, E., \& Fountain, S. (2008). Web 2.0: Conceptual foundations and marketing issues. Journal of Direct, Data and Digital Marketing Practice, 9(3), 231-244.

Cox, C., Burgess, S., Sellitto, C., \& Buultjens, J. (2009). The Role of User-Generated Content in Tourists' Travel Planning Behavior. Journal of Hospitality Marketing \& Management, 18(8), 743-764.

De Valck, K., Van Bruggen, G., \& Wierenga, B. (2009). Virtual communities: a marketing perspective. Decision Support Systems, 47(3), 185-203.

Decrop, A. (2006). Vacation decision making. Wallingford, UK: CABI Publishing.

Del Chiappa, G. (2011). Trustworthiness of Travel 2.0 applications and their influence on tourist behaviour: an empirical investigation in Italy. In Law, R., Fuchs, M., \& Ricci, F. (Eds.), Information and Communication Technologies in Tourism (pp. 331-342). New York, N.Y: Springer.

eMarketer. (2008). Online reviews sway shoppers. Retrieved from http://www.emarketer.com/ Article.aspx?R=100640

eMarketer. (2010). Online Leisure Travel: Six Post-Recession Trends. Retrieved from http:// www.emarketer.com/Report.aspx?code=emarketer_2000638

Facebook. (2011). Statistics. Retrieved 8 July 2011, from http://www.facebook.com/ press/info.php?statistics

Fernback, J., \& Thompson, B. (1995). Virtual communities: Abort, retry failure? Retrieved 14 January 2010, from http://www.well.com/user/hlr/texts/ VCcivil.html

Fischer, E., \& Reuber, A. R. (2011). Social interaction via new social media: (How) can interactions on Twitter affect effectual thinking and behavior? Journal of Business Venturing, 26(1), 1-18.

Gretzel, U., Fesenmaier, D., \& O'Leary, J. (2006). The transformation of consumer behaviour. Tourism Business Frontiers: Consumers, Products and Industry, 9-18.

Gretzel, U., Kang, M. H., \& Lee, W. J. (2008). Differences in consumer-generated media adoption and use: a cross-national perspective. Journal of Hospitality \& Leisure Marketing, 17(1-2), 99-120.

Gretzel, U., Yoo, K., \& Purifoy, M. (2007). Online travel review study: Role and impact of online travel reviews. Laboratory for Intelligent Systems in Tourism, Texas A \& M University. Retrieved from http://www.tripadvisor.com/pdfs/OnlineTravelReview Report.pdf

Hofstede, G. H., Hofstede, G. J., \& Minkov, M. (2010). Cultures and organizations: Software of the mind: International cooperation and its importance for survival (Rev. 3rd ed.). New York, NY: McGraw-Hill.

InternetWorldStats. (2010). Internet World Stats: Usage and Population Statistics. Retrieved from http://www.internetworldstats.com/ stats.htm

Jepsen, A. (2006). Information Search in Virtual Communities: Is it Replacing Use of Off-Line Communication? Journal of Marketing Communications, 12(4), 247-261.

Kaplan, A., \& Haenlein, M. (2010). Users of the world, unite! The challenges and opportunities of Social Media. Business Horizons, 53(1), 59-68.

Kim, W., Jeong, O. R., \& Lee, S. W. (2010). On social Web sites. Information Systems, 35(2), 215-236.

Kotler, P., Bowen, J., \& Makens, J. C. (2010). Marketing for hospitality and tourism (5th ed.). Boston, MA: Pearson Education.

Litvin, S. W., Goldsmith, R. E., \& Pan, B. (2008). Electronic word-of-mouth in hospitality and tourism management. Tourism Management, 29(3), 458-468. 
Lo, A., Cheung, C., \& Law, R. (2002). Information search behaviour of Hong Kong's inbound travelers-a comparison of business and leisure travelers, Journal of Travel \& Tourism Marketing, 13(3), 61-81.

Mack, R., Blose, J., \& Pan, B. (2008). Believe it or not: Credibility of blogs in tourism. Journal of Vacation Marketing, 14(2), 133-144.

Mangold, W., \& Faulds, D. (2009). Social media: The new hybrid element of the promotion mix. Business Horizons, 52(4), 357-365.

Mottiar, Z., \& Quinn, D. (2004). Couple dynamics in household tourism decision making: Women as the gatekeepers? Journal of Vacation Marketing, 10(2), 149-160.

Parra-López, E., Bulchand-Gidumal, J., Gutiérrez-Taño, D., \& Díaz-Armas, R. (2011). Intentions to use social media in organizing and taking vacation trips. Computers in Human Behavior, 27(2), 640-654

Poon, A. (1993). Tourism, technology and competitive strategies. Wallingford, UK: CAB International.

Rheingold, H. (1993). The virtual community: Homesteading on the electronic frontier. New York: Addison-Wesley.

Sirakaya, E., \& Woodside, A. G. (2005). Building and testing theories of decision making by travellers. Tourism Management, 26(6), 815-832.

Technorati. (2010). State of the Blogsphere 2010. Retrieved from http://technorati.com /blogging/article/state-of-the-blogosphere-2010-introduction/

TripAdvisor. (2011). Fact Sheet. Retrieved 8 September 2011, from http://www.tripadvisor. com /pages/about_us.html

Twitter. (2011). Twitter blog: \#numbers. Retrieved from http://blog.twitter.com/2011/03/ numbers.html

Um, S., \& Crompton, J. L. (1990). Attitude determinants in tourism destination choice. Annals of Tourism Research, 17 (3), 432-448.

Vermeulen, I., \& Seegers, D. (2009). Tried and tested: The impact of online hotel reviews on consumer consideration. Tourism Management, 30(1), 123-127.

Wang, Y., Yu, Q., \& Fesenmaier, D. (2002). Defining the virtual tourist community: implications for tourism marketing. Tourism Management, 23(4), 407-417.

White, L. (2010). Facebook, Friends and Photos: A Snapshot into Social Networking for Generating Travel Ideas. In N. Sharda (Ed.), Tourism Informatics: Visual Travel Recommender Systems, Social Communities, and User Interface Design (pp. 115-129). Hershey, PA: IGI Global.

Yoo, K.-H., Gretzel, U., \& Zach, F. (2011). Travel Opinion Leaders and Seekers. In R. Law, M. Fuchs \& F. Ricci (Eds.), Information and Communication Technologies in Tourism 2011 (pp. 525-535). New York, NY: Springer.

Yoo, K.-H., Lee, Y., Gretzel, U., \& Fesenmaier, D. R. (2009). Trust in travel-related consumer generated media. In: Höpken, W., Gretzel, U., \& Law, R. (Eds), Information and communication technologies in tourism 2009 (pp. 49-59). New York, NY: Springer.

Yoo, K. H., Lee, K. S., and Gretzel, U. (2007). The role of Source Characteristics in eWOM: What Makes Online Travel Reviewers Credible and Likeable? In Sigala, M., Mich, L., Murphy, J., \& Frew, A. (Eds.), Proceedings of the 14th International ENTER Conference in Ljubljana, Slovenia, January 24-26, 2007 (pp. 23-34). UK, Axon Imprint.

YouTube. (2011). Statistics. Retrieved 6 September 2011, from http://www.youtube.com /t/press_statistics

Xiang, Z., \& G Gretzel, U. (2010). Role of social media in travel information search. Tourism Management, 31(2), 179-188 